\title{
A Pós Graduação Brasileira em Turismo e em Ecoturismo como Caminho para a Sustentabilidade
}

\section{Brazilian Pos Graduation in Tourism and Ecotourism as a Path for Sustainability}

\author{
Maria Cristina Fogliatti de Sinay, Laura Sinay, Ariane Queiroga Ferreira, \\ lluska Lobo Braga
}

RESUMO: Os impactos do ecoturismo estão diretamente relacionados ao planejamento da atividade. Assim sendo, a sustentabilidade da mesma depende, ao menos parcialmente, do conhecimento acadêmico-científico sobre o assunto. Neste contexto e tendo em vista a potencialidade do turismo/ecoturismo no Brasil, este trabalho tem como objetivo verificar se a insustentabilidade do ecoturismo no Brasil é influenciada pelo reduzido número de profissionais academicamente aptos a planejar e implementar adequadamente a atividade no país. O procedimento metodológico seguido no presente artigo se embasa no delineamento do panorama acadêmico-científico da pós-graduação brasileira em turismo (incluindo o mapeamento dos cursos de mestrado e doutorado na área, com identificação das disciplinas ofertadas e temas abordados) e na incidência de trabalhos acadêmicocientíficos sobre ecoturismo no país (incluindo dissertações e teses, grupos de pesquisa do Conselho Nacional de Desenvolvimento Científico e Tecnológico CNPq e artigos publicados em periódicos científicos credenciados pela Coordenação de Aperfeiçoamento de Pessoal de Nível Superior - CAPES com foco no Brasil). Encontramos que o número de revistas, cursos de pós-graduação, disciplinas e dissertações acadêmicas no Brasil focados no ecoturismo é limitadíssimo. Assim, a análise do panorama atual permite concluir que a insustentabilidade do ecoturismo no Brasil é, de fato, parcialmente decorrente das limitações mencionadas. Assim sendo, se faz necessário ampliar o número de cursos de pós-graduação em (eco)turismo e melhor distribuí-los geograficamente pelo país, sendo fundamental que os programas (existentes e a serem criados) incluam em seus projetos pedagógicos disciplinas que contemplem o ensino do ecoturismo. Estas duas ações certamente impulsionarão a pesquisa em ecoturismo, que atualmente se encontra pouco expressiva, e promoverão a sustentabilidade da atividade.

PALAVRAS CHAVE: Educação e Formação em Turismo; Formação Superior em Ecoturismo; Planejamento Turístico e Sustentabilidade. 
ABSTRACT: The impacts of ecotourism are directly related to the planning of the activity. As such, its sustainability depends, at least to a degree, on academic and scientific knowledge on the subject. This work aims to verify if the well-known unsustainability of ecotourism in Brazil stems from the limited number of academically qualified professionals capable to plan and implement the activity in the country. The methodological procedure followed in this article is based on the presentation of a panorama of the Brazilian postgraduate programs in (eco)tourism (including master and doctoral programs in the field, with identification of the disciplines offered and topics covered) and the incidence of academic-scientific works on ecotourism in the country (including dissertations and thesis, research groups of the National Council for the Scientific and Technological Development - CNPq and articles published in scientific journals accredited by the Coordination for the Improvement of Higher Education Personnel - CAPES focusing on Brazil). We found that the number of journals, postgraduate programs, disciplines and scholarly dissertations focused on ecotourism is extremely limited. Thus, the analysis of the current panorama allows concluding that the unsustainability of ecotourism in Brazil is related to the mentioned limitations. As such, it is urgently necessary to increase the number of postgraduate programs in (eco)tourism and to improve their geographical distribution in the country, being fundamental that the existing and the new post graduation programs include in their pedagogical projects courses that contemplate ecotourism related topics. These two actions will certainly boost research in ecotourism, which is not very significant nowadays in the country, promoting the sustainability of the activity.

KEYWORDS: Tourism Education and Training; Higher Education in Ecotourism; Tourism Planning and Sustainability

\section{Introdução}

O turismo é uma das atividades econômicas mais importantes do mundo, não somente pelos recursos humanos e econômicos que movimenta e que freqüentemente propiciam o desenvolvimento regional, mas também pelas oportunidades que gera, como por exemplo, o melhor entendimento entre os povos (ROCHA et al., 2017; BONDER, 2008) e a valorização dos recursos naturais e culturais que atraem os turistas (ALVARENGA; CASTRO; FONSECA, 2018; OMT, 2003; UNWTO, 2018b). Devido aos seus benefícios, a prática do turismo vem sendo, há décadas, incentivada por governantes de diferentes países (SINAY et al., 2017). Consequentemente, o número de turistas viajando pelo mundo vem crescendo exponencialmente desde o início do século passado, tendo chegado a 1.4 bilhões de turistas internacionais em 2018 (UNWTO, 2019; SINAY; SINAY, 2020). As projeções de longo prazo da UNWTO prevêem um aumento anual de 3,3\% no número de turistas internacionais, alcançando, no ano de 2030, a marca de 1,8 bilhão de turistas.

Desta forma, este setor foi responsável pela movimentação de US\$1.340 bilhões de dólares somente no ano de 2018 (UNWTO, 2019). Esse valor representa $10 \%$ da economia mundial, e equivale a seis vezes o valor da indústria automotiva e cinco vezes o da indústria química (WTTC, 2014). Como a cada 10 turistas cria-se um posto de trabalho (UNWTO, 2018b), pode-se dizer que na atualidade o turismo gera cerca de 140 milhões oportunidades de trabalho no mundo.

Dentre os segmentos do turismo, um que se destaca pela significativa quantidade de adeptos é o turismo ecológico (BRASIL, 2018; ELECONOMISTA.ES, 
2017; SAMPAIO, 2018), ou ecoturismo como é chamado pelo mercado, que emprega esse termo para designar qualquer forma de turismo que envolva o uso ou a apreciação de recursos naturais e/ou o contato com povos indígenas. Esse tipo de turismo, que tem atraído cada vez mais adeptos, tem se destacado como uma atividade que conscientiza os visitantes quanto à importância da conservação ambiental (VALE; CARVALHO; MOREIRA, 2019).

A Organização Mundial de ecoturismo define ecoturismo como:

(..) todas as formas de turismo baseadas na natureza em que a principal motivação dos turistas é a observação e valorização da natureza, bem como as culturas tradicionais que prevalecem em áreas naturais. Ele contém recursos educacionais e de interpretação. É geralmente, mas não exclusivamente, organizado por operadores turísticos especializados para pequenos grupos. Os parceiros provedores de serviços nos destinos tendem a ser pequenos negócios de propriedade local. Minimiza os impactos negativos sobre o ambiente natural e sócio-cultural. Suporta a manutenção de áreas naturais que são usadas como atrações ecoturísticas por: (1) Gerar benefícios econômicos para as comunidades anfitriãs, organizações e autoridades que gerenciam áreas naturais com fins de conservação; (2) Proporcionar oportunidades alternativas de emprego e renda para as comunidades locais; (3) Aumentar a conscientização para a conservação de bens naturais e culturais, tanto entre moradores quanto turistas (UNWTO, 2018b).

Os princípios do ecoturismo são baseados na prática do lazer em ambientes naturais com a valorização da qualidade de vida (SANTOS et al., 2019). Na academia, o termo ecoturismo inclui o uso sustentável e indireto dos patrimônios natural e cultural de uma região, incentivando sua proteção e promovendo o bem estar das populações locais (SINAY et al., 2016).

Estima-se que, em média e no mundo, $20 \%$ dos turistas se envolvam em atividades ecoturísticas (BRASIL, 2018; WTTC, 2014), atividades que movimentam cerca de $\$ 268$ bilhões de dólares e que geram 28 milhões de postos de trabalho. Entende-se, posto que gera estes benefícios, que o ecoturismo auxilia na proteção de recursos naturais e culturais (UNWTO, 2018a). Ambientalistas vão mais longe e afirmam que atividades que aproximam pessoas urbanas da natureza ajudam a transformar a cultura consumista contemporânea numa cultura mais sustentável (SINAY et al., 2019, RIPPLE et al., 2017; LOUV, 2008).

Se por um lado o ecoturismo tem tanto potencial, por outro, em muitos destinos ecoturísticos a atividade tem-se caracterizado pelos impactos negativos que causa, incluindo conflitos fundiários, expulsão de povos nativos de seus territórios tradicionais, aumento do desmatamento para criação de estrutura turística, poluição causada pela ausência de infraestrutura básica, como coleta de resíduos e saneamento básico, da violência, da prostituição e da velocidade da mudança cultural sofrida pelos povos tradicionais (SINAY, 2002; 2008; SINAY et al. 2017a, 2017b, 2018 e 2019).

Apesar da natureza ser o "principal atrativo de destinos-tendência no Brasil" (SAMPAIO, 2018), são inúmeras as localidades marcadas no país pelos impactos 
negativos do ecoturismo, e poucas as que conseguem promover a sustentabilidade através desta atividade (SINAY, 2002 e 2008, SINAY et al., 2015).

Uma vez que os impactos do ecoturismo estão diretamente relacionados ao planejamento da atividade (BENI, 2004; KOTLER, 2000; KRIPPENDORF, 2001; PETROCCHI, 2001; PIZAM; MANSFIELD, 1995; MELO, 2011; COSTA, 2012), e que a qualidade do planejamento depende de conhecimento acadêmico acerca do ecoturismo (SINAY et al., 2015, 2018 e 2019), o objetivo deste trabalho é verificar a hipótese que a insustentabilidade ${ }^{1}$ do ecoturismo no Brasil é, ao menos parcialmente, decorrente do limitado conhecimento acadêmico-científico sobre a atividade.

Esta pesquisa se embasa nos pressupostos de que se a oferta de cursos acadêmicos nos níveis de Mestrado e Doutorado que incluem conhecimentos relacionados ao ecoturismo e de que se os estudos realizados no país sobre a atividade são insuficientes para o completo entendimento do ecoturismo, existirá então reduzido número de profissionais academicamente aptos a planejar e implementar o ecoturismo.

Para verificar se os pressupostos descritos são verdadeiros no país, se faz necessário conhecer o panorama do turismo / ecoturismo no âmbito da pósgraduação brasileira de nível superior. Tal conhecimento é importante, posto que pode ajudar a orientar o desenvolvimento acadêmico-científico da atividade em território nacional. Sem esse conhecimento é improvável que, apesar de maiores esforços, a atividade leve à sustentabilidade dos recursos que atraem os turistas às áreas naturais brasileiras (SINAY et al., 2015, 2018 e 2019, KRAEMER, 2004). Isso é especialmente importante no contexto atual no qual o Brasil está inserido, no qual a proteção dos recursos naturais não está necessariamente vinculada à qualidade de vida da população, à mitigação das mudanças climáticas ou à diminuição significativa das diversidades biológicas e culturais, mas que está vinculada apenas ao lucro que pode ser gerado através do uso destrutivo dos recursos naturais (REZENDE, 2018). Sendo o lucro proveniente do uso turístico dos recursos naturais maior do que o lucro proveniente de atividades agrícolas, mineradoras ou madeireiras, os ecossistemas do Brasil poderão ficar protegidos; do contrário, continuará a degradação dos mesmos, degradação essa que em Julho de 2019 bateu novo recorde, com aumento de $68 \%$ da área desmatada da Amazônia quando em comparação com 2018 (CARVALHO; WATANABE, 2019), apenas como exemplo dessa relação. Assim, o grande desafio do século 21 é buscar a sustentabilidade de todos os setores econômicos, em particular do turismo, pois só desta forma, pode-se alcançar o desenvolvimento sustentável da Nação.

\section{Metodologia}

O período avaliado para a construção do panorama aqui proposto vai do início das atividades dos cursos de pós-graduação e pesquisa e das origens dos periódicos na área de turismo / ecoturismo até o ano de 2018, tendo sido os dados levantados entre julho de 2018 e julho de 2019. Em relação aos Grupos de Pesquisa do $\mathrm{CNPq}$, foram selecionados aqueles certificados e atualizados no primeiro semestre de 2019.

Para analisar o panorama acadêmico da pós-graduação no Brasil foram identificadas, dentre as instituições brasileiras reconhecidas e credenciadas pela CAPES, quais ofertam cursos de pós-graduação - mestrado e doutorado - em 
turismo em geral, e em particular em ecoturismo, suas localizações e origens, assim como disciplinas, ementas, dissertações e teses efetivamente voltadas para assuntos relacionados ao ecoturismo. Os dados levantados possibilitaram verificar as percentagens de trabalhos relacionadas com temas de ecoturismo.

As dissertações e teses analisadas foram as publicadas na plataforma Sucupira e no site de Domínio Público da Capes. Buscou-se também representar a proporção de dissertações e teses em ecoturismo em relação ao total de dissertações e teses em turismo aprovadas no período de estudo entre os anos de 2016 a 2018 inclusive.

Pesquisa semelhante foi realizada no site de Grupos de Pesquisa do CNPq, levantando-se nome do grupo, instituição na qual está sediado, ano da sua instalação e temas estudados com a finalidade de verificar a representatividade de pesquisas acadêmicas na área do ecoturismo. Neste item foram identificados os grupos certificados pertencentes a área de Ciências Sociais Aplicadas e que contivessem no seu título ou no seu resumo a palavra 'turismo'. Uma vez identificados esses grupos, foram analisados seus objetivos para separar aqueles que tratam exclusivamente do ecoturismo.

Além disso, foram selecionados os periódicos científicos brasileiros com nota QUALIS entre A1 e B3 (quadriênio 2013/2016) que contém nos seus títulos a palavra 'turismo'. Sabe-se que pesquisadores da área publicam seus resultados em periódicos de outras áreas, principalmente, as de Administração e Economia, mas um dos objetivos deste trabalho é o de analisar o número de periódicos no setor, assim sendo, trabalhamos apenas com revistas contendo em seus títulos a palavra turismo. Em seguida, cada um destes periódicos foi cadastrado por título, pela instituição que o sedia, pelo seu ano de origem, pela sua periodicidade e pela nota no QUALIS. Finalmente, para cada periódico foram levantados o total de artigos produzidos desde o início da publicação da revista até o final de 2018, focados no turismo e no ecoturismo. Com a finalidade de separar a produção direcionada ao ecoturismo, foram utilizadas as seguintes palavras chaves: 'sustentabilidade', 'ambiental', 'ecológico', 'ecologia', 'ecoturismo' e 'turismo ecológico'.

\section{Panorama do turismo/ecoturismo no contexto acadêmico/científico brasileiro de nível superior}

O turismo é a mais nova área da pós-graduação Brasileira que faz parte das Ciências Sociais Aplicadas junto à Administração e as Ciências Contábeis. Os primeiros programas de pós-graduação em turismo e ecoturismo surgiram, respectivamente, nos anos 1997 e 2016; e em 2017, 10 programas de pósgraduação em turismo estavam em funcionamento (Quadro 1; Figura 1). Esses programas estão concentrados nas regiões Sudeste (3), Nordeste (4) e Sul (3) do país (Figura 2). Três desses programas oferecem Mestrado e Doutorado, e somente um é focado exclusivamente no ecoturismo. $23 \%$ desses cursos oferecem doutorado e mestrado, $23 \%$ somente mestrado profissional e os restantes, $54 \%$, mestrado acadêmico. $10 \%$ dos programas têm nota 5 conforme avaliação da CAPES, $40 \%$ nota 4 e $50 \%$ nota 3 (Quadro 1). 
Quadro 1: Instituições Brasileiras que oferecem curso de pós-graduação em turismo e ecoturismo. Frame 1: Brazilian Institutions offering postgraduate courses in Tourism and Ecotourism.

\begin{tabular}{|c|c|c|c|c|c|}
\hline NOME & INSTITUIÇÃO & $\begin{array}{l}\text { ANO DE } \\
\text { ORIGEM }\end{array}$ & NÍVEL & REGIÃO & $\begin{array}{l}\text { AVALIAÇÃO } \\
\text { CAPES }\end{array}$ \\
\hline Ecoturismo e Conservação & $\begin{array}{l}\text { Universidade Federal do } \\
\text { Estado do Rio de Janeiro } \\
\text { (UNIRIO) }\end{array}$ & 2016 & $\begin{array}{c}\text { Mestrado } \\
\text { Profissional }\end{array}$ & Sudeste & 4 \\
\hline Turismo & $\begin{array}{l}\text { Universidade Federal } \\
\text { Fluminense (UFF) }\end{array}$ & 2015 & Mestrado & Sudeste & 3 \\
\hline Turismo & $\begin{array}{c}\text { Universidade de São Paulo } \\
\text { (USP) }\end{array}$ & 2014 & Mestrado & Sudeste & 4 \\
\hline Hotelaria e Turismo & $\begin{array}{l}\text { Universidade Federal de } \\
\text { Pernambuco (UFPE) }\end{array}$ & 2017 & Mestrado & Nordeste & 3 \\
\hline Turismo & $\begin{array}{c}\text { Instituto Fed. De Educação, } \\
\text { Ciência e Tecnologia de } \\
\text { Sergipe (IFS) }\end{array}$ & 2016 & $\begin{array}{l}\text { Mestrado } \\
\text { Profissional }\end{array}$ & Nordeste & 3 \\
\hline \multirow[t]{2}{*}{ Turismo } & Universidade Federal do & 2008 & Mestrado & \multirow[t]{2}{*}{ Nordeste } & 4 \\
\hline & $\begin{array}{c}\text { Rio Grande do Norte } \\
\text { (UFRN) }\end{array}$ & 2014 & Doutorado & & 4 \\
\hline Gestão de Negócios Turísticos & $\begin{array}{c}\text { Universidade Estadual do } \\
\text { Ceará (UECE) }\end{array}$ & 2012 & $\begin{array}{l}\text { Mestrado } \\
\text { Profissional }\end{array}$ & Nordeste & 3 \\
\hline Turismo & $\begin{array}{c}\text { Universidade Federal do } \\
\text { Paraná (UFPR) }\end{array}$ & 2013 & Mestrado & Sul & 3 \\
\hline \multirow[t]{2}{*}{ Turismo e Hospitalidade } & Universidade de Caxias do & 2000 & Mestrado & \multirow[t]{2}{*}{ Sul } & 4 \\
\hline & Sul $(\mathrm{UCS})$ & 2015 & Doutorado & & 4 \\
\hline \multirow[t]{2}{*}{ Turismo e Hotelaria } & Universidade do Vale do & 1997 & Mestrado & \multirow[t]{2}{*}{ Sul } & 5 \\
\hline & Itajaí (UNIVALI) & 2013 & Doutorado & & 5 \\
\hline
\end{tabular}

Fonte: Elaboração própria.

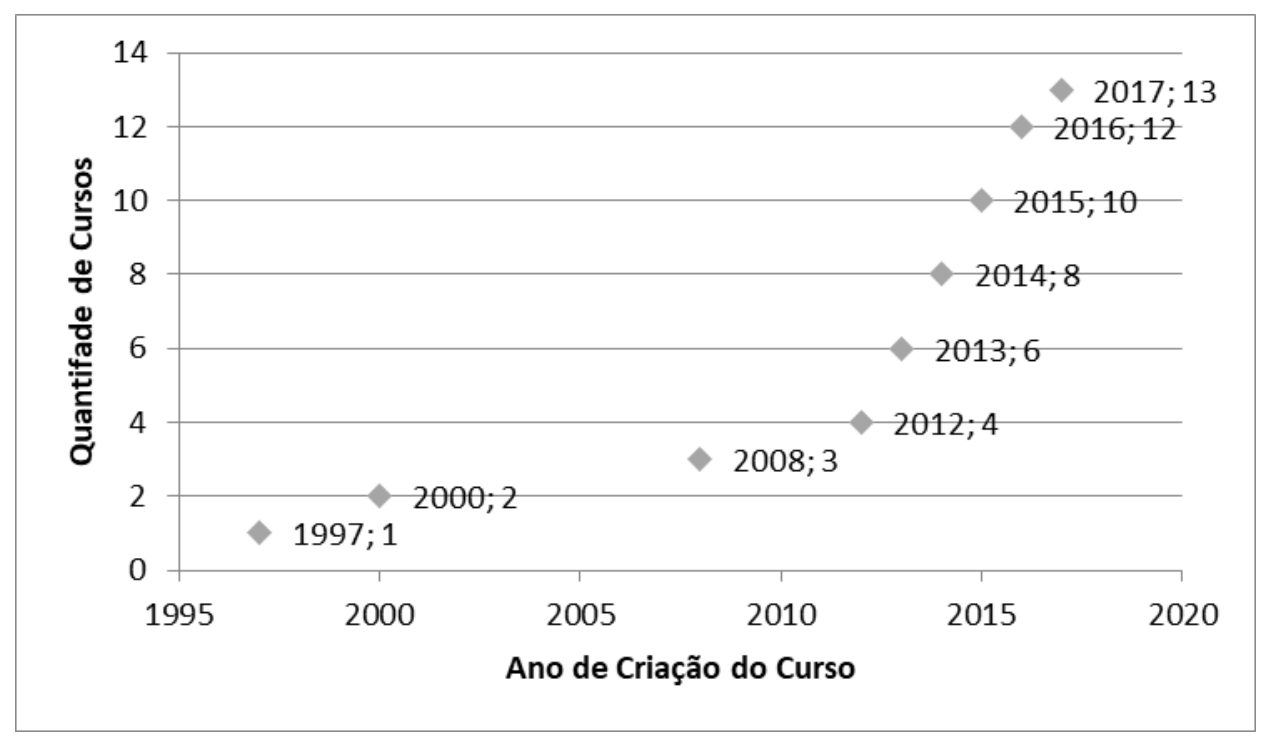

Figura 1: Evolução do número de Cursos de turismo no Brasil.

Figure 1: Evolution of the number of Brazilian Tourism courses

Fonte: Elaboração própria.

Source: Own elaboration. 


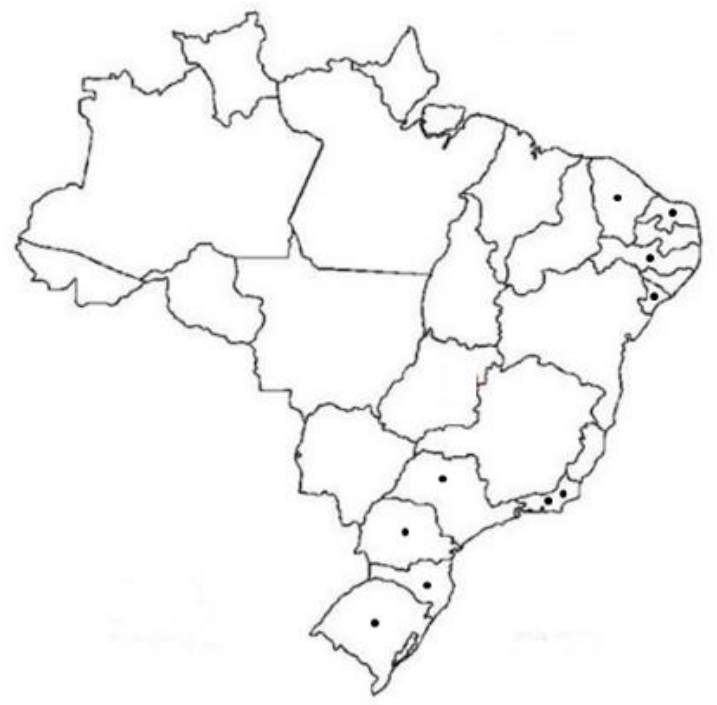

Figura 2: Localização regional das Instituições no Brasil.

Figure 2: Regional localización of Brazilian Institutions.

Fonte: Elaboração própria.

Source: Own elaboration.

Das 316 disciplinas oferecidas pela pós-graduação brasileira em turismo, apenas $13(4 \%)$ estão diretamente relacionadas ao ecoturismo (Quadro 2) e $18(6 \%)$ contém no seu programa algum tema relacionado ao tema (Quadro 3).

Quadro 2: Disciplinas específicas de ecoturismo.

Frame 2: Specific Ecotourism Disciplines.

Disciplinas específicas de ecoturismo

Educação Ambiental

Áreas protegidas e legislação ambiental brasileira

Ecoturismo, conservação e sustentabilidade

Metodologia científica das ciências ambientais aplicadas ao ecoturismo

Política brasileira de conservação da natureza

Sustentabilidade: conceitos e práticas

Técnicas de planejamento e gestão aplicados ao ecoturismo e à conservação de áreas naturais

Tópicos especiais em monitoramento ambiental

Povos tradicionais e sustentabilidade

Geoconservação

Turismo e unidades de conservação

Turismo e meio ambiente

Turismo comunitário

Fonte: Elaboração própria.

Source: Own elaboration. 
Quadro 3: Disciplinas que contém temas sobre ecoturismo

Frame 3: Subjects containing themes on Ecotourism

Disciplinas que contém temas de ecoturismo

Turismo, relações socioculturais e desenvolvimento local

Meio ambiente e turismo

Aspectos socioculturais e socioambientais do turismo

Lazer e turismo em áreas protegidas

Turismo e natureza

Sustentabilidade e turismo

Gestão de destinos turísticos de sol e praia

Planejamento e gestão do turismo

Turismo e sociedade

Turismo e impactos socioambientais

Cartografia e geoprocessamento aplicado ao turismo

Turismo, sociedade e meio ambiente

Destinos turísticos: planejamento estratégico e participativo

Estudos avançados em educação ambiental no turismo e hotelaria

Estudos avançados em turismo no espaço rural

Estudos avançados em turismo e meio ambiente

Planejamento e gestão do destino turístico

Paisagem e infraestrutura no ordenamento do espaço turístico.

Fonte: Elaboração própria.

Source: Own elaboration.

Entre os anos 2016 e 2018, 177 dissertações e teses em turismo foram aprovadas, mas apenas dez delas (5\%) foram especificamente em ecoturismo. Todas são dissertações de mestrado; dois são trabalhos teóricos e oito são estudos de caso (Quadro 4).

Quadro 4: Dissertações

Frame 4: Dissertations

Dissertações classificadas como estudos de caso:

O direito à paisagem natural e à proteção dos destinos turísticos no litoral Cearense

Turismo em lagoas costeiras e a valorização ambiental em Osório, Rio Grande do Sul

Turismo de aventura no planalto da Ibipaba: a oferta de serviços nas cidades de Tianguá/CE e Ubajara/CE

Ecoturismo e paisagem: a composição visual da paisagem como recurso para o ecoturismo no extremo

Sul do Brasil - RS

O turismo na natureza do Rio Grande do Sul: a partir da atuação das agências de turismo

O turismo e o desenvolvimento local em terras indígenas e unidades de conservação de São Gabriel da

Cachoeira - AM

Turismo em lagoas costeiras e a valorização ambiental em Osório, Rio Grande do Sul

Turismo de aventura em Osório, Rio Grande do Sul: uma possibilidade para consolidação de um destino Dissertações classificadas como estudos teóricos:

Destinos turísticos inteligentes sob a perspectiva da teoria Ator-Rede: contribuições para as pesquisas e turismo no Brasil

Turismo e educação ambiental: uma análise a partir de instrumentos legais e projetos pedagógicos de cursos de graduação

Fonte: Elaboração própria.

Source: Own elaboration.

Dos 115 grupos de pesquisa em turismo certificados encontrados na pesquisa realizada no site do CNPq apenas 12 são especificamente de ecoturismo. Destes, somente 3 pertencem a instituições com programas de pós-graduação em turismo: Universidade Federal do Estado do Rio de Janeiro - UNIRIO, Instituto Federal de Educação, Ciência e Tecnologia de Sergipe - IFS e Universidade do Vale do Itajaí UNIVALI. O título destes grupos, respectivas descrições, ano de origem e 
instituições na que se sediam são apresentados na Quadro 5. Os nove grupos de pesquisa restantes, pertencem a instituições que ou oferecem cursos de graduação em turismo ou que simplesmente realizam pesquisas sobre o tema.

Quadro 5: Grupos de pesquisa em ecoturismo.

Frame 5: Ecotourism research groups

\begin{tabular}{|c|c|c|c|}
\hline Nome do grupo & Descrição & Ano & Instituição \\
\hline $\begin{array}{c}\text { Ecoturismo e } \\
\text { Desenvolvimento }\end{array}$ & $\begin{array}{l}\text { Política brasileira de conservação da natureza; Unidades de } \\
\text { conservacão e grandes projetos de investimento. }\end{array}$ & 2014 & UNIRIO \\
\hline $\begin{array}{l}\text { Turismo no espaço } \\
\text { rural: planejamento e } \\
\text { gestão - GPTER }\end{array}$ & $\begin{array}{l}\text { Análise, Projeto e Desenvolvimento de Sistemas; ecoturismo; } \\
\text { Educação Patrimonial; Engenharia Agrícola; Espanhol } \\
\text { Aplicado ao turismo; Gestão de Meios de Hospedagem; } \\
\text { História Aplicada ao turismo; Patrimônio Cultural aplicado } \\
\text { ao turismo; Planejamento e Gestão do turismo; turismo de } \\
\text { Aventura; turismo Rural. }\end{array}$ & 2011 & IFS \\
\hline $\begin{array}{l}\text { Turismo, espaço e } \\
\text { sociedade - TES }\end{array}$ & $\begin{array}{c}\text { Comunidades tradicionais: memória, resistência e direitos } \\
\text { humanos; Patrimônios Alimentares; Planejamento dos } \\
\text { Espaços Turísticos. }\end{array}$ & 2002 & UNIVALI \\
\hline
\end{tabular}

Fonte: Elaboração própria.

Source: Own elaboration.

Em relação aos periódicos, há só um direcionado especificamente ao ecoturismo (RBECOTUR). Além disso, não há periódicos em turismo classificados como A1 e há um único periódico (RBTUR) classificado como A2 (Quadro 6).

Quadro 6: Quadro de Revistas Brasileiras em turismo/ecoturismo

Frame 6: Table of Brazilian Magazines on Tourism / Ecotourism

\begin{tabular}{|c|c|c|c|c|c|c|}
\hline Revista & $\begin{array}{c}\text { Instituiçã } \\
\text { o }\end{array}$ & $\begin{array}{c}\text { Ano } \\
\text { inicio }\end{array}$ & Periodicidade & $\begin{array}{c}\text { Quali } \\
\text { s }\end{array}$ & $\begin{array}{l}\text { Total de } \\
\text { artigos }\end{array}$ & $\begin{array}{l}\text { Artigos em } \\
\text { ecoturismo }\end{array}$ \\
\hline $\begin{array}{l}\text { Revista Brasileira de } \\
\text { Pesquisa em Turismo }\end{array}$ & ANPTUR & 2007 & Quadrimestral & A2 & 260 & 17 \\
\hline Caderno Virtual de Turismo & UFRJ & 2001 & Quadrimestral & B1 & 445 & 51 \\
\hline $\begin{array}{l}\text { Revista de turismo - Visão } \\
\text { e Ação }\end{array}$ & Univali & 2010 & Quadrimestral & B1 & 441 & 24 \\
\hline Revista Turismo em Análise & USP & 1990 & Quadrimestral & B1 & 587 & 171 \\
\hline $\begin{array}{l}\text { Revista Acadêmica } \\
\text { Observatório de Inovação } \\
\text { do Turismo }\end{array}$ & Unigranrio & 2006 & Semestral & B2 & 189 & 5 \\
\hline $\begin{array}{l}\text { Rosa dos Ventos - Turismo } \\
\text { e Hospitalidade }\end{array}$ & UCS & 2009 & Trimestral & B2 & 290 & 22 \\
\hline $\begin{array}{l}\text { ReAT - Revista Eletrônica } \\
\text { de Administração e Turismo }\end{array}$ & UFPEL & 2012 & Semestral & B3 & 84 & 0 \\
\hline $\begin{array}{l}\text { Reuna - Revista de } \\
\text { Economia, Administração e } \\
\text { Turismo }\end{array}$ & UMA & 1996 & Trimestral & B3 & 420 & 4 \\
\hline $\begin{array}{l}\text { RBecotur - Revista } \\
\text { Brasileira de Ecoturismo }\end{array}$ & Unifesp & 2008 & Trimestral & B3 & 337 & 267 \\
\hline $\begin{array}{l}\text { Revista de Turismo } \\
\text { Contemporâneo }\end{array}$ & UFRN & 2013 & Semestral & B3 & 90 & 2 \\
\hline $\begin{array}{l}\text { RITUR - Revista } \\
\text { Iberoamericana de Turismo }\end{array}$ & UFAL & 2011 & Semestral & B3 & 192 & 7 \\
\hline TOTAIS & & & & & 3335 & 570 \\
\hline
\end{tabular}

Fonte: Elaboração própria.

Source: Own elaboration. 
Dentre os temas dos artigos levantados, considerando tanto estudos teóricos quanto estudos de caso, os que mais se destacam são turismo em áreas protegidas, turismo em parques urbanos, e atrativos naturais.

Dos 3.335 artigos publicados por esses 11 periódicos, apenas 570 (17\%) contemplam o ecoturismo. Salta a vista, como era de se esperar, a alta percentagem, $79 \%$, de artigos em ecoturismo publicados pela RBECOTUR. Ela é seguida pela Revista turismo em Análise que apresenta $29 \%$ da sua produção em ecoturismo; os demais periódicos apresentam participação abaixo dos $8 \%$, chegando um deles a $0 \%$.

\section{Discussão e considerações finais} seguir.

As hipóteses apresentadas na Introdução desta pesquisa estão discutidas a

\section{A oferta de cursos acadêmicos específicos em ecoturismo é limitada em termos de número de cursos e de distribuição geográfica?}

Em termos de número de cursos, há somente um programa de pósgraduação focado no ecoturismo no Brasil e, embora 10 programas de pósgraduação em turismo estivessem funcionando em 2018, nenhum dos outros 9 programas oferecia disciplinas específicas sobre ecoturismo. Em relação à distribuição geográfica, não há programas de pós-graduação em turismo nas regiões Norte e Centro Oeste.

Os dados, portanto, confirmam que a oferta de cursos acadêmicos específicos em ecoturismo (mestrado e doutorado) é quase irrelevante se considerada as dimensões do país, e os de turismo são, de fato, muito limitados em termos de número de cursos e de distribuição geográfica.

\section{As pesquisas realizadas no país sobre o ecoturismo são insuficientes para 0 completo entendimento do ecoturismo no contexto brasileiro?}

Entre as 177 dissertações e teses em turismo que foram aprovadas entre os anos 2016 e 2018, não há nenhuma tese de doutorado focada no ecoturismo, e entre as 10 dissertações de mestrado focadas no ecoturismo somente duas são teóricas. Embora 10\% dos grupos de pesquisa do CNPq em turismo sejam focados especificamente no ecoturismo, somente um quarto desses grupos (3) pertence a instituições com cursos de pós-graduação em turismo, o que leva ao questionamento sobre o importante link entre pesquisa e ensino.

Em relação aos periódicos, não há periódicos acadêmicos em turismo classificados como $\mathrm{A} 1$ e há somente um periódico direcionado especificamente ao ecoturismo. Embora quase 20\% dos artigos publicados nos periódicos brasileiros de turismo sejam focados no ecoturismo, quase $80 \%$ deles foram publicados em revistas classificadas como B3. Pode-se afirmar, então, que as pesquisas realizadas no país sobre ecoturismo são insuficientes para o completo entendimento do tema. 


\section{O limitado conhecimento técnico-científico sobre o ecoturismo no contexto brasileiro é um obstáculo à sustentabilidade do ecoturismo no Brasil?}

Não há um só autor que argumente que o planejamento seja supérfluo nas atividades do turismo e do ecoturismo. Ao contrário, todos os pesquisadores que falam de sustentabilidade no contexto do turismo afirmam que o planejamento é fundamental e que deve levar em consideração todo o sistema afetado direta e indiretamente pela atividade. Devido à complexidade do planejamento necessário, a necessidade de robusto conhecimento técnico-científico é evidente. Mas, como demonstrado, esse conhecimento é ainda muito incipiente na pós-graduação no Brasil, tornando-se evidente que a limitação do conhecimento técnico-científico sobre o ecoturismo se constitui um obstáculo à sustentabilidade do ecoturismo no Brasil.

O diagnóstico realizado possibilitou uma série de constatações úteis que deveriam incentivar esforços e até políticas públicas em relação à necessidade de aumentar o número de cursos de pós-graduação em turismo no Brasil que, de fato, se empenhem em incluir nos seus projetos pedagógicos disciplinas que contemplem o ensino do ecoturismo tendo em vista as peculiaridades desta atividade e os benefícios que a mesma pode trazer.

O Brasil, país de dimensões continentais e com potencial enorme para se beneficiar do ecoturismo, apresenta regiões não atendidas no que se refere a cursos de pós-graduação em turismo, e as atendidas contam apenas com no máximo 4 cursos. Do escasso número de cursos de pós-graduação em turismo / ecoturismo no país pode-se deduzir que há um número reduzido de profissionais academicamente aptos a planejar e implementar o ecoturismo no Brasil.

Em relação aos periódicos brasileiros dedicados tanto a temas gerais de turismo, quanto específicos sobre o ecoturismo, ainda são poucos, o que leva a pesquisadores do setor a publicarem seus resultados em outras áreas correlatas, como as de Administração, Economia e Finanças. Nesse contexto, deveria haver esforço para aumentar o número de periódicos direcionados ao assunto, assim como em revisar as classificações atuais dos periódicos existentes dando uma melhor distribuição das notas. Isto certamente poderá atrair um maior número de publicações.

Se forem levados em consideração os estudos apresentados na introdução deste artigo que apontam que pelo menos $20 \%$ dos turistas se envolvem com atividades ecoturísticas, movimentando mais de 260 bilhões de dólares e gerando em torno de 28 milhões de postos de trabalho no mundo, fica evidente que esta atividade deveria ser reconhecida como sendo muito importante, tanto pelo potencial econômico da mesma, quanto pelo fato da qualidade dos locais - destinos ecoturísticos - dependerem da qualidade do seu planejamento, o que só é possível com uma formação acadêmica/ científica mais expressiva.

O forte potencial econômico da atividade turística, em particular ecoturística, fomenta 0 desenvolvimento regional conforme demonstrado por vários pesquisadores. Se esta atividade estiver bem fundamentada nos campos acadêmico e científico com cursos de pós-graduação que permitam que a atividade científica se manifeste e se intensifique e que um maior número de profissionais esteja apto para planejar adequadamente a atividade, ter-se-á um caminho para a sustentabilidade do turismo que ocorre em áreas naturais e ou tradicionalmente habitadas, onde 0 
ecoturismo tende a ocorrer. Nas condições atuais do país este caminho carece, ainda, de atenção quanto as políticas públicas de incentivo.

\section{Notas:}

${ }^{1}$ Isto é, que tende a não se sustentar ambiental, social e ou economicamente.

\section{Referências}

ALVARENGA, L.; CASTRO, P. T. A.; FONSECA, I. C. M. Contribuições à proteção jurídica do patrimônio geológico no Brasil: Locais e Áreas Especiais de Interesse Turístico como espaços de geoconservação. Terr@Plural, Ponta Grossa, v. 12, n. 2 p. 188-200, 2018.

BENI, M. C. Análise Estrutural do turismo. 10aed. Atual. São Paulo: SENAC, 2004. BONDER, N. Tirando os sapatos: O caminho de Abraão, um caminho para o outro. Rio de Janeiro: Rocco, 2008.

BRASIL. Ministério do turismo. Anuário Estatístico de turismo 2017 - Ano Base 2016. Brasília: MTur, $2018 . \quad$ Disponível em: $<$ http://www.dadosefatos.turismo.gov.br/2016-02-04-11-53-05/item/347anu\%C3\%A1rio-estat\%C3\%ADstico-de-turismo-2017-ano-base-2016/347anu\%C3\%A1rio-estat\%C3\%ADstico-de-turismo-2017-ano-base-2016.html>. Acesso em: 01 jun. 2020.

CARVALHO, D.; WATANABE, P. Marcos Pontes também questiona dados do Inpe e chama diretor para conversa. Folha de Sao Paulo, 2019. Disponível: $<$ https://www1.folha.uol.com.br/ambiente/2019/07/marcos-pontes-tambem-

questiona-dados-do-inpe-e-chama-diretor-para-conversa.shtml>. Acesso em: 27 mar 2020

COSTA, L. A. A imagem da cidade do Rio de Janeiro para os paulistanos: fatores que influenciam na motivação de visita desta demanda à cidade. Caderno Virtual de turismo. Rio de Janeiro, v. 12, n. 1, p. 1-16, 2012.

ELECONOMISTA.ES. El ecoturismo crece por encima del convencional y cada vez atrae a más extranjeros. Economía. 2017. Disponível em: $<$ https://www.eleconomista.es/economia/noticias/8628434/09/17/El-ecoturismocrece-por-encima-del-convencional-y-cada-vez-atrae-a-mas-extranjeros.html>. Acesso em: 09 mar. 2020.

GIL, A. C. Métodos e técnicas de pesquisa social. São Paulo: Atlas, 2008.

KOTLER, P. Administração de Marketing. 10 ed. São Paulo: Prentice Hall, 2000

KRAEMER, M. E. P. A Universidade do Século XXI rumo ao Desenvolvimento Sustentável. Revista Eletrônica de Ciência Administrativa (RECADM). v. 3, n. 2, p. 1-21, 2004.

KRIPPENDORF, J. Sociologia do turismo: para uma nova compreensão do lazer e das viagens. São Paulo: ALEPH, 2001.

LOUV, R.. Last child in the woods: Saving our children from nature-deficit disorder. London: Atlantic books, 2008. 
MELO, N. R. de. A aplicação da Análise SWOT no planejamento turístico de uma localidade: $O$ caso de Araxá, MG. Caderno Virtual de turismo. Rio de Janeiro, v. 11, n. 2, p. 164-176, 2011.

OMT - Organização Mundial de turismo. Guia de desenvolvimento do turismo Sustentável. Porto Alegre: Bookman, 2003.

PETROCCHI, M. C. Gestão de pólos turísticos. São Paulo: Futura, 2001

PIZAM, A.; MANSFIELD, Y. Tourism, crime and international security issues. England: Wiley, 1995.

REZENDE, C. Em Roraima, Bolsonaro defende exploração econômica de terras indígenas. 0 Estado de São Paulo. 2018. Disponivel em: $<$ https://politica.estadao.com.br/noticias/eleicoes,em-roraima-bolsonaro-defendeexploracao-economica-de-terras-indigenas,70002266170>. Acesso em: 03 jun. 2020.

RIPPLE, W. J.; WOLF, C.; NEWSOME, T. M.; GALETTI, M.; ALAMGIR, M.; CRIST, E.; MAHMOUD, M. I.; LAURANCE, W. F. World scientists' warning to humanity: A second notice. BioScience, v. 67, n. 12, p. 1026-1028, 2017.

ROCHA, E. ; SINAY, L. ; PREVOT, R. O Turismo como Ferramenta de Transformação: Traçando Caminhos para a Paz. Revista Acadêmica Observatório de Inovação do Turismo, v. 11, p. 92, 2017.

SAMPAIO, V. 2018: natureza é principal atrativo de destinos-tendência no Brasil. Ministério do turismo. Brasília: MTur, 2018. Disponível em: $<$ http://www.turismo.gov.br/\%C3\%BAltimas-not\%C3\%ADcias/10664-2018-natureza\%C3\%A9-principal-atrativo-de-destinos-tend\%C3\%AAncia-no-brasil.html>. Acesso em: 01 jun. 2020.

SANTOS, H. Q. S.; OLIVEIRA, S. D. de; PASSOS, F. V. de A. A percepção do visitante na cachoeira Véu das Noivas - Parque Estadual do Cunhambebe - RJ. Revista Acadêmica Observatório de Inovação do turismo, v. 13, n. 2, p. 77-99, 2019.

SINAY, L. Ecoturismo e Culturas Tradicionais - Estudo de Caso: Martim de Sa. 2002. Dissertação (Mestrado UFRJ/CFCH/IP/EICOS) Universidade Federal do Rio de Janeiro. Rio de Janeiro: Brasil, p. 1-95, 2002.

SINAY, L. Modelling And Forecasting Cultural And Environmental Changes. Thesis. (PhD The University of Queensland). Quensland: Australia, 2008. Disponível em: $<$ https://drive.google.com/file/d/OBzlTclGTXAEjeFZnUnJoX1YxcXc/view?usp=sharin g>..Acesso em: 20 nov 2020

SINAY, L.; ZAÚ, ANDRÉ ; VILLANI, R. ; SIMÕES, B. F. T ; RODRIGUES, C. G. O. ; MORAES, CAMILA ; FIGUEIREDO, CARLOS ; ANDRADE, D. F. ; SILVA, L. H. S. ; SANTOS, L. N. ; PONCIANO, L. C. M. O. ; MORAES, L. A. F. ; OLIVEIRA, M. A. ; SAMPAIO, M. C. ; KREPSKY, N. ; CARDOSO, R. S. ; SARTORI, R. A. Mestrado Profissional em Ecoturismo e Conservação. 2015.

SINAY, L.; SINAY, M. C. F. de; PASSOS, F. V. de A.; BRAGA, I. L.; REVHEIM. V. C. C. A. Panorama atual do ecoturismo na Academia Brasileira. Anais do Encontro Nacional de turismo de Base Local, 14., Manaus, novembro, 2016. 
SINAY, L.; SINAY, M. C. F. de; CARTER, R. W. B.; PASSOS, F. V. de A. Povos Tradicionais, Áreas Protegidas e turismo: Um Estudo de Caso Brasileiro de 15 Anos de Mudança Cultural. Ambiente \& Sociedade, São Paulo. v. 22, 2019.

SINAY, L.; CARTER, R. W. B.; SINAY, M. C. F. de. Povos tradicionais, áreas protegidas, turismo e políticas públicas: o papel emergente da academia. Caderno Virtual de turismo. Rio de Janeiro. v. 18, n. 3, 2018.

SINAY, L.; SINAY, M. C. F. de; PASSOS, F. V. de A.; BRAGA, I. L. Megaeventos, legado e sustentabilidade: o caso da Cidade do Rio de Janeiro. Revista Brasileira de ecoturismo (RBEcotur), São Paulo, v. 10, n. 3, 2017.

SINAY, L.; SINAY, M. C. F. de.; CARTER, R.W (Bill); Martins, A.C. Who is Writing the Science behind the Management of Protected Areas? Annals of Ecology and Environmental Science, Vol.3(3), pp.18-24; 2019.

SINAY, L.; THAM, A.; SCHAFFER, V.; CARTER, R.W.(BILL); SCOTT, N. Does Ecotourism Influence Environmental Awareness? A Methodological Approach Based on Virtual Reality and Physiological Responses. Annals of Ecology and Environmental Science, Vol.4(1), pp.1-10; 2020.

SINAY, L.; SINAY, M. C. F de. How to Better Manage Tourism on Pandemic-Times? Moving Forward on a Discussion We Should Have Had Before the 2020 Crisis. Preprints. Disponível: <https://www.preprints.org/manuscript/202010.0487/v1>. Acesso 31 out 2020

UNWTO. Ecotourism and Protected Areas. Madrid: UNWTO, 2018a. Disponível em: $\quad$ https://www.unwto.org/sustainable-development/ecotourism-and-protectedareas. Acesso em: 12 nov. 2019.

UNWTO. UNWTO Tourism Highlights - 2018 Edition. Madrid: UNWTO, 2018b. DOI: <https://doi.org/10.18111/9789284419876. Acesso em: 12 nov. 2019.

UNWTO. International Tourist Arrivals Reach 1.4 billion Two Years Ahead of Forecasts. Madrid: UNWTO, 2019. Disponível em: <https://www2.unwto.org/pressrelease/2019-01-21/international-tourist-arrivals-reach-14-billion-two-years-aheadforecasts>. Acesso em: 12 nov. 2019.

VALE, T. F. do; CARVALHO, K. G. de; MOREIRA, J. C. A reputação online em áreas protegidas: análise do Parque Nacional Marinho de Fernando de Noronha (Pernambuco, Brasil). Revista Acadêmica Observatório de Inovação do turismo, v. 13, n. 3, p. 113-134, 2019.

WTTC. Travel \& Tourism Economic Impact 2014. Londres: WTTC, 2014. Disponível em: <http://www.ontit.it/opencms/export/sites/default/ont/it/documenti/files/ONT 2014-0331 03008.pdf>. Acesso em: 12 nov. 2019.

ZOUAIN, D. M.; PEREIRA JÚNIOR, A. N.; SOUZA, L. A. V. de; DUARTE, A. L. F. Os (des) avanços nos níveis de indicadores de competitividade de destinos turísticos indutores brasileiros: o caso de São Raimundo Nonato. Gestão \& Regionalidade, v. 35, n. 104, p. 124-143, 2019. 
Maria Cristina Fogliatti de Sinay: Pesquisadora Independente, Brasil

E-mail: cristinasinay@gmail.com

Link para o currículo Lattes: http://lattes.cnpq.br/4705136602818227

Laura Sinay: Universidade Federal do Estado do Rio de Janeiro, Rio de Janeiro, RJ, Brasil

E-mail: laura.sinay@unirio.br

Link para o currículo Lattes: http://lattes.cnpq.br/1227278208156191

Ariane Queiroga Ferreira: Universidade do Grande Rio, Duque de Caxias, RJ, Brasil

E-mail: ariqferreira@gmail.com

Link para o currículo Lattes: http://lattes.cnpq.br/9269463360033332

Iluska Lobo Braga: Universidade Federal de Rondônia, Porto Velho, RO, Brasil

E-mail: iluska.lobo@unir.br

Link para o currículo Lattes: http://lattes.cnpq.br/5471499041003382

Data de submissão: 03 de setembro de 2020

Data de recebimento de correções: 10 de setembro de 2020

Data do aceite: 22 de outubro de 2020

Avaliado anonimamente 